\title{
Translation and Standardization of the Extended Influence Behavior Questionnaire (IBQ-G) in a Greek Sample
}

\author{
Konstantina Tyrovola ${ }^{1}$, Vicky Papanikolaou ${ }^{1}$, Dimitrios Adamis ${ }^{2}$ \\ ${ }^{1}$ Department of Health Service Management, National School of Public Health, Athens, Greece; \\ ${ }^{2}$ Research and Academic Institute of Athens, Athens, Greece. \\ Email: tyrovola.tina@gmail.com

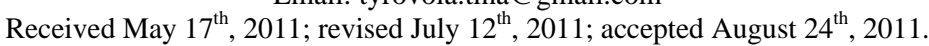

\begin{abstract}
The purpose of this study was to translate in Greek the IBQ-G and investigate the validity and reliability of the Greek version. The Greek translation of IBQ-G has been given in a sample of employees in two public organizations at two different time points. A questionnaire which has been created for the purpose of this study also has been administered to assess similar influences behaviors. The convergent validity of the Greek version of IBQ-G was very good in both occasions. Similarly, examination of test-retest reliability with paired t-tests showed that most, but not all of the IBQ-G scales were stable across the time ( $p>0.05)$. The Greek translated IBQ-G is a valid and reliable measurement. However, the stability over the time of all IBQ-G scales was not supported from this study. The Greek version of IBQ-G can be used for managerial, research, audit, and to facilitate multinational research.
\end{abstract}

Keywords: IBQ-G, IBQ-G Greek Translation, Influence Tactics, Validity, Reliability

\section{Introduction}

It has been recognized for more than three decades now that influence is essential for effective performance by managers (Kipnis, Schmidt, \& Wilkinson, 1980). A manager to be successful needs to influence others to carry out requests, support proposals, and implement decisions (Schriesheim \& Hinkin, 1990; Yukl \& Falbe, 1990; Yukl \& Tracey, 1992). The success of an attempt by one person (the "agent") to influence another person ("the target") depends to a great extent on the influence tactics used by the agent (Farrell \& Schroder, 1996; Yukl, Falbe, \& Youn, 1993).

Influence tactics can be classified according to their primary purpose and time frame (Yukl, Seifert, \& Chavez, 2008) to: 1) proactive tactics which are used in an attempt to influence someone to carry out an immediate request that needs very often the cooperation and assistance of other people inside and outside the organization (Yukl, Chavez, \& Seifert, 2005). They are especially important in organizations that have moved away from hierarchical forms of structure to more empowered forms, or have cooperative arrangements with other organizations, so in these situations the agent has little authority over target persons (Yukl, et al., 2005). 2) Impression management tactics which are used to create a favorable image and build a better relationship (e.g. Gardner \& Martinko, 1988; Kumar \& Beyerlein, 1991; Wayne, Liden, Graef, \& Ferris, 1997), and 3) political tactics which are used to influence policy decisions or the allocation of scarce resources (Kacmar \& Baron, 1999; Pfeffer, 1992). Some types of influence tactics can be used for more than one purpose, but a tactic may not be equally effective for different purposes (Yukl \& Chavez, 2002).

The influence behavior of managers has been studied with several research methods including coding of qualitative descriptions of influence behavior (e.g., from critical incidents or diaries), manipulation of influence tactics in laboratory experiments (e.g., with actors, role play exercises, or scenarios), and manipulation of influence behavior in field experiments, for example with feedback and training (Fu \& Yukl, 2000; Yukl, Fu, \& Mc Donald, 2003). The most often used method to study proactive influence tactics was a descriptive list of influential behaviors. (Yukl et al., 2003). However, since 1980 different questionnaires started to be developed for survey research on proactive influence tactics but two of them have been used widely (Yukl et al., 2008).

The first questionnaire, the Profile of Organizational Influence Strategies (POIS) has been developed by Kipnis et al., (1980) which is an agent self-report questionnaire, and measure eight influence tactics (rationality, exchange, ingratiation, assertiveness, coalition, upward appeal, blocking and sanctions). A revised version of the agent POIS, with six influence tactics, (rationality, exchange, ingratiation, assertiveness, coalition, upward and appeal) has been developed ten years later by Schriesheim \& Hinkin (1990). Both the original and revised versions of the agent POIS have been used in many studies of upward influence (e.g. Acquadro, Conway, Hareendran, \& Aaronson, 2008; Aydin \& Pehlivan, 2010; Deluga, 1988, 1991; Wayne et al., 1997).

The second questionnaire, the Influence Behavior Questionnaire (IBQ) has been developed by Yukl \& Tracey, (1992) to be used as a target questionnaire. It measures target perceptions of an agent's use of proactive tactics in attempts to influence the target respondent (Seifert \& Yukl, 2010; Yukl et al., 2008). This early version of the IBQ measured ten influence tactics (six were similar to ones in the POIS; rational persuasion, exchange, ingratiation, pressure, coalition, and upward appeals), and four influence tactics based on leadership and power literature (consultation, inspirational appeals, personal appeals, and legitimating). Further validation of this early version (Yukl, Lepsinger, \& Lucia, 1992) provided support for nine of the ten tactics.Ten years later the IBQ was revised (IBQ-R) and extended to include two more tactics, apprising and collaboration (Yukl \& Seifert, 2002). More recently the 11 tactic scales have been reordered and the last version has been named as IBQ-G (Yukl et al., 2008). A number of studies has examined the construct validity of the IBQ-G and the psychometric properties of 
the tool, and it has been reported that IBQ-G is a valid, reliable and comprehensive measure of proactive influence tactics (e.g. Charbonneau, 2004; Yukl et al., 2005; Yukl et al., 2003). The objectives of the IBQ items are to measure attitudes that influence the target person to comply with an unspecified request, to carry out a task, to provide assistance, to support or implement a proposed change, or to do a personal favor for the agent. In the IBQ-G a respondent rates how often a designated agent (e.g. the boss) uses each of the 11 proactive tactics while attempting to influence the respondent. Each tactic scale has 4 items. The content of the items reflects findings in descriptive research on common influence objectives and the tactics used for each type of objective (Yukl et al., 1993; Yukl, Guinan, \& Sottolano, 1995). Each item has five anchored response choices: "I can't remember him/her ever using this tactic with me" = 1, "He/she very seldom uses this tactic with me" $=2$, "He/she occasionally uses this tactic with me" $=3$, "He/she uses this tactic moderately often with me" $=4$, "He/she uses this tactic very often with me" $=5$. The scale score for a tactic is the mean of the item scores. IBQ-G is a simple and fast to administer tool and can easily identify individual and organizational behaviors on which the success of an organization partially depends. Extensive use of the IBQ in feedback workshops for managers has shown that respondents rarely leave any items unanswered (Seifert \& Yukl, 2010; Seifert, Yukl, \& Mc Donald, 2003). However, it has been suggested that if there are any missing data the remedies include computing the mean item score using only the available data for that tactic, or not including the respondent in the analysis for a scale if there are missing data for more than one item in the scale (Seifert \& Yukl, 2010).

The IBQ has several advantages over the POIS. Only a few studies (e.g., Erez \& Rim, 1982; Kipnis et al., 1980) have used the POIS to measure influence behavior directed at subordinates or peers, but there is no systematic evidence or validation studies for its use for downward influences (Kipnis \& Schmidt, 1988). However, the POIS has been excessively validated for assessing tactics used in upward influence attempts (Farmer \& Maslyn, 1999; Farmer, Maslyn, Fedor, \& Goodman, 1997; Schriesheim \& Hinkin, 1990). Furthermore, self-reports of behavior are not always accurate for rating of a person's behavior by other people (Seifert \& Yukl, 2010). Unlike the POIS, the IBQ is validated as a target instrument for studying downward and lateral influence (Yukl et al., 2005; Yukl et al., 2008). Finally, the IBQ includes a broader range of influence tactics to be measured in contrast to POIS which includes less tactics, and some of those tactics which are not included in POIS, perhaps are more important for managers and professionals (Charbonneau, 2004; Yukl et al., 2008).

Organizations' effectiveness depends in part on the quality of work relationships and the agent ought to use influence tactics that may be crucial not only to his/her personal success, but also may contribute to the effectiveness of the organization (Egri, Ralston, Murray, \& Nicholson, 2000). Evidences for the effectiveness of influenced behaviors are limited in Greece. One important reason is the lack of a valid instrument. The lack of evidence creates difficulties for many agents to understand the complex relationships among performance determinants and to recognize the actions that can be taken to influence subordinates in a beneficial way. Although some instruments are cultural-bounded there are evidence that IBQ is a valid instrument in different cultures (Fu et al., 2004; Kennedy, Fu, \& Yukl, 2003).

Thus, the primary aim of this study is to translate and validate the IBQ-G scale in a Greek sample. We have hypothesized that there will be no differences between the Greek IBQ-G version and a reference scale (see below) which measure similar influence tactics.

\section{Method}

\section{Translation}

After having obtained the permission for translation from professor Yukl, the original English version of IBQ-G instrument has been translate to Greek language according to recommended procedures (Acquadro et al., 2008; Brislin, 1970). The scale was translated into Greek and then back into English independently by two translators. Any inconsistency was discussed with linguistic experts not related to the study. The final version was administered to ten different, again not related with the study, university students to test for linguistic adaptations, grammatical, typing, spelling or other mistakes. Integration of relevant corrections led to the final Greek language version that was administered to the participants of the study.

\section{Participants}

Participants were all (50) employees in two public organizations located in the Athens Metropolitan area and they were asked to rate the influence behavior of a designated agent (their superior). There was not particular method or influences for the selection of the organizations but given that there was not randomization our sample can be characterized as a convenience sample. No exclusion criteria were used.

\section{Measurements}

1) Demographics: data collected on age, gender, and in which organization the participant was worked.

2) The translated Greek version of IBQ-G.

3) Reference questionnaire. As a reference questionnaire a new scale was created the Influence Tactics Scale (ITS) based on the eleven influence tactics that were similar to ones in the IBQ-G (rational persuasion, exchange, inspirational appeal, legitimating, apprising, pressure, collaboration, ingratiation, consultation, personal appeals and coalition). Those influence tactics have differed wording and different order from the original IBQ-G. Besides, the four items of each one scale of the original IBQ-G have been merged in one item. Each item of the ITS was rated on a Likert scale from 1 to 5 ("Never" = 1, "Very seldom" = 2, "Occasionally" = 3, "Moderately often" = 4, "Very often" = 5).

\section{Procedure}

The two questionnaires (IBQ-G and ITS) were given to the participants in two different occasions which were four weeks apart (T1 and T2) in order to test the test-retest reliability of the IBQ-G Greek version. The process involved in both occasions was identical. The participants were asked to fill first the ITS questionnaire, then they gave it back to the researcher and the administration of the second questionnaire (IBQ-G) was followed.

\section{Ethics}

As the project did not involve any harm or risk of the participants, approval of Research Ethics Committee was not sought. However, permission was obtained from the Head of Human Resources Department of each organization. Anonym- 
ity has been ensured by using codes and removing the names during the data entry for analyses.

\section{Analysis of Data}

All data were coded and entered into SPSS v17 for Windows. Evidence of convergent validity was demonstrated by comparing the IBQ-G scales for eleven tactics with the ITS scale for similar tactics using correlations. The test-retest reliability was investigated by comparing the initial IBQ-G and ITS scores with the subsequent scores provided after the 4 weeks period by using paired tests.

\section{Results}

From the 50 returning questionnaires, 10 had been excluded as they were uncompleted. Thus, the participant rate was $80 \%$. From the remained $(n=40)$ participants, 22 were males and 18 were females. The mean age of the participants was 37 (SD 8.2).

\section{Convergent Validity}

The convergent validity was assessed by using Pearson correlation (r). Each scale of the IBQ-G was assessed for correlation with the relevant item of the ITS at T1 and T2 time points. The results are shown in "Table 1" and "Table 2".

It can be seen from the tables that the convergent validity of the Greek version of IBQ-G is very good in both occasions. Each scale of the IBQ-G is highly correlated with the ITS items in a significant level $(\mathrm{p}<0.001)$. For instance Rational Persuasion has high correlation in both times while Ingratiation has the lowest but still significant.

\section{Test-Retest Reliability}

An indicator of reliability is the extent to which ratings remain stable over an interval of time in which the behavior is not likely to change. Test-retest reliability for the tactic scales in the IBQ-G was assessed by using paired t-test between the T1 point time and $\mathrm{T} 2$ for each scale of the IBQ-G measurement.
Paired $\mathrm{t}$ test for the tactics of collaboration $(\mathrm{t}=0.006, \mathrm{df}=39, \mathrm{p}$ $<0.01)$, ingratiation $(\mathrm{t}=0.001, \mathrm{df}=39, \mathrm{p}<0.01)$, and consultation $(\mathrm{t}=0.010$, $\mathrm{df}=39, \mathrm{p}<0.01)$ showed significant differences (thus they have changed during time). However, other influence tactics like Rational Persuasion, Exchange, Inspirational Appeal have been unchanged during the time ( $p>0.05$ ). The results of paired t-test of IBQ-G are shown in "Table 3".

Similar paired t-test was used for each item of the ITS to assess the pattern of the changes. Paired t test for the tactics of ingratiation $(\mathrm{t}=0.001, \mathrm{df}=39, \mathrm{p}<0.01)$ and coalition $(\mathrm{t}=$ 0.002 , df $=39, \mathrm{p}<0.01$ ) showed significant differences. The results of paired t-test of ITS are shown in Table 4. Thus, the tactics of ingratiation are changed in both scales during time.

Further we investigate the test-retest reliability as a correlation of each scale at the two time points, using Pearson correlations. The reliability of each scale respectively is: for Rational Persuasion 98\%, for Exchange 96\%, for Inspirational Appeal 96\%, Legitimating 99\%, Apprising 97\%, Pressure 94\%, Collaboration 96\% Ingratiation 94\%, Consultation 95\%, Personal Appeals 96\%, and for Coalition 96\%. Thus, the test-retest reliability for each scale was high.

\section{Discussion}

The results show that the Greek translation of IBQ-G is a valid and reliable measurement. In this study, we examined the criterion-related validity of IBQ-G, and specifically, the convergent validity. Convergent validity is provided by the very good correlation in both occasions of the administered tool, between the eleven scales measuring similar tactics in the IBQ- G and the second questionnaire which we created for the needs of the project and used as a "gold standard". Those results are comparable to the previous studies (e.g. Yukl et al., 2005; Yukl \& Seifert, 2002).

Reliability is one important psychometric property of a questionnaire because it demonstrates the value and functionality of it. A number of studies have examined the reliability of the IBQ-G (Yukl et al., 2005; Yukl \& Seifert, 2002) and they found

Table 1.

Convergent validity for similar tactics in the target IBQ-G and the target ITS at T1 $(N=40)$.

\begin{tabular}{|c|c|c|c|}
\hline $\begin{array}{c}\text { Rational Persuasion } \\
\text { IBQ X ITS, } r=0.91 \\
\text { P }<0.001\end{array}$ & $\begin{array}{c}\text { Exchange } \\
\text { IBQ X ITS, } \mathrm{r}=0.84 \\
\mathrm{P}<0.001\end{array}$ & $\begin{array}{c}\text { Inspirational Appeal } \\
\text { IBQ X ITS, } r=0.85 \\
\text { P }<0.001\end{array}$ & $\begin{array}{c}\text { Legitimating } \\
\text { IBQ X ITS, } r=0.87 \\
\mathrm{P}<0.001\end{array}$ \\
\hline $\begin{array}{c}\text { Apprising } \\
\text { IBQ X ITS, } \mathrm{r}=0.89 \\
\mathrm{P}<.001\end{array}$ & $\begin{array}{c}\text { Pressure } \\
\text { IBQ X ITS, } \mathrm{r}=0.72 \\
\mathrm{P}<0.001\end{array}$ & $\begin{array}{c}\text { Collaboration } \\
\text { IBQ X ITS, } r=0.69 \\
\text { P }<0.001\end{array}$ & $\begin{array}{c}\text { Ingratiation } \\
\text { IBQ X ITS, } r=0.058 \\
\mathrm{P}<0.001\end{array}$ \\
\hline $\begin{array}{c}\text { Consultation } \\
\text { IBQ X ITS, } r=0.84 \\
P<0.001\end{array}$ & $\begin{array}{c}\text { Personal Appeals } \\
\text { IBQ X ITS, } \mathrm{r}=0.77 \\
\mathrm{P}<0.001\end{array}$ & $\begin{array}{c}\text { Coalition } \\
\text { IBQ X ITS, } \mathrm{R}=0.64 \\
\mathrm{P}<0.001\end{array}$ & \\
\hline
\end{tabular}

Table 2.

Convergent validity for similar scales in the target IBQ-G and the target ITS T2 $(N=40)$.

\begin{tabular}{|c|c|c|c|}
\hline $\begin{array}{c}\text { Rational Persuasion } \\
\text { IBQ X ITS, } r=0.86 \\
\text { P }<0.001\end{array}$ & $\begin{array}{c}\text { Exchange } \\
\text { IBQ } X \text { ITS, } r=0.82 \\
\mathrm{P}<0.001\end{array}$ & $\begin{array}{c}\text { Inspirational Appeal } \\
\text { IBQ X ITS, } r=0.77 \\
\text { P }<0.001\end{array}$ & $\begin{array}{c}\text { Legitimating } \\
\text { IBQ X ITS, } r=0.74 \\
\mathrm{P}<0.001\end{array}$ \\
\hline $\begin{array}{c}\text { Apprising } \\
\text { IBQ } X \text { ITS, } r=0.85 \\
\mathrm{P}<0.001\end{array}$ & $\begin{array}{c}\text { Pressure } \\
\text { IBQ X ITS, } \mathrm{r}=0.85 \\
\mathrm{P}<0.001\end{array}$ & $\begin{array}{c}\text { Collaboration } \\
\text { IBQ X ITS, } r=0.65 \\
\text { P }<0.001\end{array}$ & $\begin{array}{c}\text { Ingratiation } \\
\text { IBQ X ITS, } r=0.69 \\
\mathrm{P}<0.001\end{array}$ \\
\hline $\begin{array}{c}\text { Consultation } \\
\text { IBQ X ITS, } r=0.80 \\
\text { P }<0.001\end{array}$ & $\begin{array}{c}\text { Personal Appeals } \\
\text { IBQ X ITS, } \mathrm{r}=0.73 \\
\mathrm{P}<0.001\end{array}$ & $\begin{array}{c}\text { Coalition } \\
\text { IBQ X ITS. } r=0.85 \\
\mathrm{P}<0.001\end{array}$ & \\
\hline
\end{tabular}


Table 3.

Test-retest reliability of IBQ- $G(N=40)$.

\begin{tabular}{|c|c|c|c|c|c|c|c|c|}
\hline Influence Tactics & Mean & S.D & S. E. M & \multicolumn{2}{|c|}{ 95\% CI Low Upper } & $\mathrm{t}$ & df & Sig.* \\
\hline Rational Persuasion & 0.006 & 0.230 & 0.036 & -0.067 & 0.080 & 0.172 & 39 & 0.864 \\
\hline Exchange & -0.043 & 0.277 & 0.044 & -0.131 & 0.046 & -0.970 & 39 & 0.338 \\
\hline Inspirational Appeal & 0.001 & 0.283 & 0.045 & -0.091 & 0.091 & 0.001 & 39 & 1.00 \\
\hline Legitimating & -0.019 & 0.173 & 0.027 & -0.074 & 0.037 & -0.684 & 39 & 0.498 \\
\hline Apprising & -0.069 & 0.320 & 0.051 & -0.171 & 0.034 & -1.35 & 39 & 0.182 \\
\hline Pressure & 0.063 & 0.348 & 0.055 & -0.049 & 0.174 & 1.14 & 39 & 0.263 \\
\hline Collaboration & -0.133 & 0.283 & 0.045 & -0.222 & -0.041 & -2.93 & 39 & 0.006 \\
\hline Ingratiation & 0.469 & 0.354 & 0.056 & 0.355 & 0.582 & 8.37 & 39 & $<0.001$ \\
\hline Consultation & -0.119 & 0.277 & 0.044 & -0.207 & -0.030 & -2.71 & 39 & 0.010 \\
\hline Personal Appeals & -0.025 & 0.304 & 0.048 & -0.122 & 0.072 & -0.520 & 39 & 0.606 \\
\hline Coalition & -0.081 & 0.274 & 0.043 & -0.169 & 0.006 & -1.88 & 39 & 0.068 \\
\hline
\end{tabular}

Note: *in bold significant differences $(\mathrm{P}<0.05)$.

Table 4.

Test-retest reliability of ITS $(N=40)$.

\begin{tabular}{|c|c|c|c|c|c|c|c|c|}
\hline Influence Tactics & Mean & S. D & S. E. M & \multicolumn{2}{|c|}{ 95\% CI Low Upper } & $\mathrm{t}$ & $\mathrm{df}$ & Sig.* \\
\hline Rational Persuasion & 0.050 & 0.450 & 0.071 & -0.094 & 0.194 & 0.703 & 39 & 0.486 \\
\hline Exchange & -0.100 & 0.591 & 0.093 & -0.289 & 0.089 & -1.07 & 39 & 0.291 \\
\hline Inspirational Appeal & -0.075 & 0.350 & 0.055 & -0.187 & 0.037 & -1.36 & 39 & 0.183 \\
\hline Legitimating & -0.025 & 0.531 & 0.083 & -0.195 & 0.145 & -0.298 & 39 & 0.767 \\
\hline Apprising & 0.001 & 0.506 & 0.080 & -0.162 & 0.162 & 0.001 & 39 & 1.00 \\
\hline Pressure & -0.125 & 0.757 & 0.120 & -0.367 & 0.117 & -1.04 & 39 & 0.303 \\
\hline Collaboration & 0.050 & 0.389 & 0.062 & -0.074 & 0.174 & 0.813 & 39 & 0.421 \\
\hline Ingratiation & 0.375 & 0.490 & 0.078 & 0.218 & 0.532 & 4.84 & 39 & $<0.001$ \\
\hline Consultation & -0.050 & 0.221 & 0.035 & -0.121 & 0.021 & -1.43 & 39 & 0.160 \\
\hline Personal Appeals & -0.075 & 0.474 & 0.075 & -0.227 & 0.077 & -1.00 & 39 & 0.323 \\
\hline Coalition & -0.400 & 0.778 & 0.123 & -0.649 & -0.151 & -3.25 & 39 & 0.002 \\
\hline
\end{tabular}

Note: *in bold significant differences $(\mathrm{P}<0.05)$.

high inter-rater reliability. In this study, we examined another indicator of reliability which indicates the extent to which ratings remain stable over an interval of time. Test-retest reliability of the tactic scales in the IBQ-G was assessed by scores' comparison between the first and the second occasion (after 4 weeks). However, stability was not found adequate because 3 of 11 tactics, collaboration, ingratiation and consultation, changed after the 4 weeks period. Similarly, in the second questionnaire (ITS), ratings for tactics of ingratiation and coalition also changed. Although this finding shows that the test-retest reliability of the IBQ-G is good (as both questionnaires changed similarly to the same direction, and the correlations were excellent) this result is contrary to those of previous findings (Yukl \& Seifert, 2002; Yukl et al., 2008), who reported that the stability of all 11 scales were satisfactory. In particular, (Yukl et al., 2008), reported that almost all tactics remained unchanged even after a ten week period ( $p>0.7$, no significant statistical differences) except for the tactics of legitimating and 
coalition, whose levels of $\mathrm{p}$ were also above 0.6. Nevertheless, it seems from our results that the IBQ-G is a reliable instrument and given that test-retest reliability is influenced from the time interval it is worth for future research, the stability of the eleven tactics to be evaluated further in less and more longer time intervals.

In addition our results showed that we have a rate response of $80 \%$. Although from our experience the IBQ-G is a fast and easily administered tool we have missing data of one or more scales in a rate of $20 \%$. We avoid inputting missing values but this finding is to some extend contradictory to the previous finding by Seifert \& Yukl, (2010), Seifert et al., (2003) who reported that they rarely had unanswered items. However, a possible explanation is that their sample was managers while ours mixed of managers and lower degree employees. Thus perhaps the response rate of IBQ-G dependent also in the hierarchy in one organization.

Cross cultural studies in English speaking countries have also found that IBQ-G is unaffected by culture for example New Zealand, Thailand, India ( $\mathrm{Fu}$ et al., 2004). In addition the IBQ-G was translated in different languages e.g. in French by Lacassagne, (Fu et al., 2004), Turkish by Pasa (2000), but has not been validated. However, direct translation of an instrument from one language to another does not guarantee content equivalence of the translated scale (Cha, Kim, \& Erlen, 2007). Because of the later, our primary aim was not only to translate but also to investigate the psychometric properties of the Greek version of IBQ-G. The Greek version of IBQ-G apart of its usefulness in Greek organizations, can also be used for others purposes. Previous research found that the proactive tactics were meaningful to managers in other countries, and there was substantial agreement about the relative effectiveness of most tactics for influencing subordinates, peers, and bosses (Kennedy et al., 2003). Thus, because IBQ-G is an internationally recognized and used scale, we think that the most important benefit of this translation and standardization is that the Greek version of IBQ-G can be used as a tool for multinational leadership research and comparison with other countries.

Limitations of the study. This study is limited to that the Greek version of IBQ-G has been evaluated in only two public organizations. Because the IBQ was developed to measure influence attempts between members of an organization, the tactic scales perhaps are needed to be validated for influence attempts in other different organization in Greece (e.g. Private organizations).

\section{Conclusion}

From this work it seems that the Greek translated IBQ-G is a valid and reliable instrument for the measurement of downward influence tactics. In addition, the stability over the time of all IBQ-G scales was not supported from this study. This finding needs further investigation. Finally this work suggests that the Greek version of IBQ-G can be used for managerial, research, and audit purposes, and to be used in multinational research.

\section{References}

Acquadro, C., Conway, K., Hareendran, A., \& Aaronson, N. (2008). Literature review of methods to translate health-related quality of life questionnaires for use in multinational clinical trials. Value in Health, 11, 509-521. doi:10.1111/i.1524-4733.2007.00292.x

Aydin, I., \& Pehlivan, Z. (2010). Strategies and personality types used by primary school principals in Turkey to influence teachers (Ankara case). Procedia Social and Behavioral Sciences, 2, 3652-3659. doi:10.1016/j.sbspro.2010.03.568

Brislin, R. (1970). Back-translation for cross-cultural research. Journal of Cross-Cultural Psychology, 1, 185-216. doi:10.1177/135910457000100301

Cha, E.-S., Kim, K. H., \& Erlen, J. A. (2007). Translation of scales in cross-cultural research: Issues and techniques. Journal of Advanced Nursing, 58, 386-395. doi:10.1111/j.1365-2648.2007.04242.x

Charbonneau, D. (2004). Influence tactics and perceptions of transformational leadership. Leadership and Organization Development Journal, 25, 565-576. doi:10.1108/01437730410561459

Deluga, R. J. (1988). Relationship of transformational and transactional leadership with employee influencing strategies. Group \& Organization Studies, 13, 456-467. doi:10.1177/105960118801300404

Deluga, R. J. (1991). The relationship of upward-influencing behavior with subordinate impression management characteristics. Journal of Applied Social Psychology, 21, 1145-1160. doi:10.1111/j.1559-1816.1991.tb00463.x

Egri, C. P., Ralston, D. A., Murray, C. S., \& Nicholson, J. D. (2000). Managers in the NAFTA countries: A cross-cultural comparison of attitudes toward upward influence strategies. Journal of International Management, 6, 149-171. doi:10.1016/S1075-4253(00)00016-8

Erez, M., \& Rim, Y. (1982). The relationship between goals, influence tactics, and personnel and organizational variables. Human Relations, 35, 871-878. doi:10.1177/001872678203501004

Farmer, S. M., \& Maslyn, J. (1999). Why are styles of upward influence neglected? Making the case for a configurational approach to influences. Journal of Management, 25, 653-682. doi:10.1177/014920639902500503

Farmer, S. M., Maslyn, J. M., Fedor, D. B., \& Goodman, J. S. (1997). Putting upward influence strategies in context. Journal of Organizational Behavior, 18, 17-42.

doi:10.1002/(SICI)1099-1379(199701)18:1<17::AID-JOB785>3.0.C $\underline{0 ; 2-9}$

Farrell, M. A., \& Schroder, B. (1996). Influence strategies in organizational buying decisions. Industrial Marketing Management, 25, 293-303. doi:10.1016/0019-8501(95)00131-X

Fu, P. P., Kennedy, J., Tata, J., Yukl, G., Bond, M. H., Peng, T.-K., \& Cheosakul, A. (2004). The impact of societal cultural values and individual social beliefs on the perceived effectiveness of managerial influence strategies: A meso approach. Journal of International Business Studies, 35, 284-305. doi:10.1057/palgrave.jibs.8400090

Fu, P. P., \& Yukl, G. (2000). Perceived effectiveness of influence tactics in the united states and china. The Leadership Quarterly, 11, 251-266. doi:10.1016/S1048-9843(00)00039-4

Gardner, W. L., \& Martinko, M. J. (1988). Impression management in organizations. Journal of Management, 14, 321-338. doi:10.1177/014920638801400210

Kacmar, K. M., \& Baron, R. A. (1999). Organizational politics: The state of the field, links to related processes, and an agenda for future research. Research in Personnel and Human Resources Management, 17, 1-39.

Kennedy, J., Fu, P. P., \& Yukl, G. (2003). Influence tactics across twelve cultures. In W. Mobley, \& P. Dorfman (Eds.), Advances in global leadership (Vol. 3, pp. 127-148). Greenwich: JAI Press Inc.

Kipnis, D., \& Schmidt, S. M. (1988). Upward influence styles: Relationship with performance evaluations, salary, and stress. Administrative Science Quarterly, 33, 528-542. doi:10.2307/2392642

Kipnis, D., Schmidt, S. M., \& Wilkinson, I. (1980). Intra-organizational influence tactics: Exploration in getting one's way. Journal of Applied Psychology, 65, 440-452. doi:10.1037/0021-9010.65.4.440

Kumar, K., \& Beyerlein, M. (1991). Construction and validation of an instrument for measuring ingratiatory behaviors in organizational settings. Journal of Applied Psychology, 76, 619-627. doi:10.1037/0021-9010.76.5.619

Pasa, S. F. (2000). Leadership influence in a high power distance and collectivist culture. Leadership and Organization Development Journal, 21, 414-426. doi:10.1108/01437730010379258

Pfeffer, J. (1992). Managing with power: Politics and influence in organizations. Boston: Harvard Business School Press.

Schriesheim, C. A., \& Hinkin, T. R. (1990). Influence tactics used by subordinates: A theoretical and empirical analysis and refinement of 
the Kipnis, Schmidt, and Wilkinson subscales. Journal of Applied Psychology, 75, 246-257. doi:10.1037/0021-9010.75.3.246

Seifert, C. F., \& Yukl, G. (2010). Effects of repeated multi-source feedback on the influence behavior and effectiveness of managers: A field experiment. The Leadership Quarterly, 21, 856-866. doi:10.1016/j.leaqua.2010.07.012

Seifert, C. F., Yukl, G., \& Mc Donald, R. (2003). Effects of multisource feedback and a feedback facilitator on the influence behavior of managers towards subordinates. Journal of Applied Psychology, 88, 561-569. doi:10.1037/0021-9010.88.3.561

Wayne, S. J., Liden, R., Graef, I., \& Ferris, G. (1997). The role of upward influence tactics in human resource decisions. Personnel Psychology, 50, 979-1006. doi:10.1111/j.1744-6570.1997.tb01491.x

Yukl, G., \& Chavez, C. (2002). Influence tactics and leader effectiveness. In L. Neider, \& C. Schriesheim (Eds.), Leadership: Research in management (Vol. 2, pp. 139-165). Charlotte: Information Age Publishing.

Yukl, G., Chavez, C., \& Seifert, C. F. (2005). Assessing the construct validity and utility of two new influence tactics. Journal of Organizational Behavior, 26, 705-725. doi:10.1002/job.335

Yukl, G., \& Falbe, C. M. (1990). Influence tactics in upward, downward, and lateral influence attempts. Journal of Applied Psychology, 75, 132-140. doi:10.1037/0021-9010.75.2.132

Yukl, G., Falbe, C. M., \& Youn, J. Y. (1993). Patterns of influence behavior for managers. Group and Organization Management, 18, 5-28. doi:10.1177/1059601193181002

Yukl, G., Fu, P. P., \& Mc Donald, R. (2003). Cross-cultural differences in perceived effectiveness of influence tactics for initiating or resisting change. Applied Psychology: An International Review, 52, 68-82. doi:10.1111/1464-0597.00124

Yukl, G., Guinan, P. J., \& Sottolano, D. (1995). Influence tactics used for different objectives with subordinates, peers, and superiors. Group and Organization Management, 20, 272-296. doi:10.1177/1059601195203003

Yukl, G., Lepsinger, R., \& Lucia, A. (1992). Preliminary report on development and validation of the influence behavior questionnaire. In K. Clark, M. B. Clark, \& D. Campbell (Eds.), Impact of leadership (pp. 417-427). Greensboro: Center for Creative Leadership.

Yukl, G., \& Seifert, C. (2002). Preliminary validation of an extended version of the Influence Behavior Questionnaire. The Society for Industrial Organizational Psychology Meetings, Toronto, April 2002.

Yukl, G., Seifert, C. F., \& Chavez, C. (2008). Validation of the extended Influence Behavior Questionnaire. The Leadership Quarterly, 19, 609-621. doi:10.1016/j.leaqua.2008.07.006

Yukl, G., \& Tracey, B. (1992). Consequences of influence tactics used with subordinates, peers, and the boss. Journal of Applied Psychology, 77, 525-535. doi:10.1037/0021-9010.77.4.525 